\title{
Peptidyl-Prolyl Cis-Trans Isomerase FKBP9
}

National Cancer Institute

\section{Source}

National Cancer Institute. Peptidyl-Prolyl Cis-Trans Isomerase FKBP9. NCI Thesaurus.

Code C143129.

Peptidyl-prolyl cis-trans isomerase FKBP9 (570 aa, $63 \mathrm{kDa}$ ) is encoded by the human FKBP9 gene. This protein is involved in chaperone-mediated protein folding. 